was not strongly associated with risk of breast cancer. Our finding that menses returned at a median duration of six months in women breast feeding for up to nine months agrees with prospectively collected data in breast feeding women." However, our finding that menses returned at a median of 12 months in women breast feeding for more than one year does not agree with the prospectively collected data ${ }^{11}$ and suggests that recall of return of menses is biased upwards. This may partly explain why return of menses is not a good predictor of risk of breast cancer. Detailed questions on reasons for breast feeding and for stopping, use of supplementary feeds, and introduction of solid food may elucidate this issue further in future studies.

This study was funded by the Cancer Research Campaign and the Medical Research Council, through their grant to the Institute of Cancer Research, and by the Imperial Cancer Research Fund. We thank Peggy Wan for programming help with this analysis. We thank Angela Umali and Melanie Cumpston for preparing the manuscript.

Members of the United Kingdom national case-control study group were from Imperial Cancer Research Fund's Epidemiology Unit, Oxford; Section of Epidemiology, Institute of Cancer Research, Sutton; Department of Public Health and Primary Care, University of Oxford; Department of Public Health and Policy, London School of Hygiene and Tropical Medicine; Department of Public Health Medicine and Epidemiology, University of Nottingham Medical School; and Department of Preventive Medicine, University of Southern California School of Medicine. Principal investigators were C E D Chilvers, $\mathrm{K}$ McPherson, J Peto, M C Pike, and M P Vessey. Study coordinators were B Crossley, C Hermon, and C Taylor.

A full list of investigators and acknowledgments has been published.'

1 United Kingdom National Case-Control Study Group. Oral contraceptive use and breast cancer risk in young women. Lancet 1989;: $973-82$.

2 United Kingdom National Case-Control Study Group. Oral contraceptive use and breast cancer risk in young women: subgroup analyses. Lance 1990;335:1507-9.

3 Breslow NE, Day NE. Statistical methods in cancer research. The analysis of casecontrol studies. Lyons: International Agency for Cancer Research, 1980. (IARC scientific publication No 32.)

4 Byers T, Graham S, Rzepka T, Marshall J. Lactation and breast cance evidence for a negative association in premenopausal women. $A m$ Epidemiol 1985;121:664-74.

5 Layde PM, Webster LA, Baughman AL, Wingo PA, Rubin GL, Ory HW. The independent associations of parity, age at first full term pregnancy, and duration of breastfeeding with the risk of breast cancer. $\mathcal{f}$ Clin Epidemiol 1989;42:963-73.

6 McTiernan A, Thomas DB. Evidence for a protective effect of lactation on risk of breast cancer in young women. Am f Epidemiol 1986;124:353-8.

7 Adami H-O, Bergstrom R, Lund E, Meirik O. Absence of association between reproductive variables and the risk of breast cancer in young women in Sweden and Norway. Br 7 Cancer 1990;62:122-6.

8 Siskind V, Schofield F, Rice D, Bain C. Breast cancer and breastfeeding: results from an Australian case-control study. Am J Epidemiol 1989;130: 229-36.

9 Kvale G, Heuch I. Lactation and cancer risk: is there a relation specific to breast cancer? I Epidemiol Community Health 1987;42:30-7

10 London SJ, Colditz GA, Stampfer MJ, Willett WC, Rosner BA, Corsano K, et al. Lactation and risk of breast cancer in a cohort of US women. $A m$ f Epidemiol 1990;132:17-26.

11 Gray RH, Campbell OM, Apelo R, Eslami SS, Zacur H, Ramos RM, et al. Risk of ovulation during lactation. Lancet 1990;335:25-9.

(Accepted 5 May 1993)

\title{
Factors associated with lack of awareness of HIV infection before diagnosis of AIDS
}

\author{
Kholoud Porter, Patrick G Wall, Barry G Evans
}

\section{Abstract}

Objective-To identify characteristics of people likely to be unaware of their HIV infection before diagnosis of AIDS defining disease.

Design-Survey of continuing surveillance of voluntarily reported AIDS cases.

Subjects -4127 adults with AIDS diagnosed during 1989-92 and reported to the Public Health Laboratory Service AIDS Centre.

Setting-England and Wales.

Main outcome measure-Lack of prolonged awareness of infection before diagnosis of AIDS, defined as an interval of nine months or less between first positive test result and diagnosis of AIDS.

Results-Of 3556 adults with known dates of first positive HIV test result and AIDS diagnosis, 1742 $(49 \%)$ had been unaware of their infection for up to nine months before AIDS was diagnosed. Lack of awareness was independently and positively associated with infection through heterosexual contact (odds ratio $4.46,95 \%$ confidence interval 3.15 to 6.33), AIDS reported outside the Thames regions $(1.64,1.38$ to 1.96$)$, and being non-white $(1.99,1.51$ to $2 \cdot 61$ ). Women were less likely to be unaware than men $(0.50,0.33$ to 0.76$)$, and people diagnosed in 1992 were least likely to be unaware $(0.48,0.39$ to $0 \cdot 60$ ). Those aged 25-49 years at diagnosis were less likely to be unaware than those aged 15-24 years and those aged 50 and over.

Conclusions-People with certain characteristics are more likely than others to be unaware of their HIV infection before AIDS is diagnosed and are therefore less likely to receive prophylaxis. Methods for educating this heterogeneous group need to be investigated.

\section{Introduction}

In the decade since the AIDS epidemic was first recognised in the United Kingdom much has been learnt about the management of people with HIV infection. As their infection progresses infected patients become increasingly susceptible to opportunistic infections. Trials have shown the benefits of intervention with antiretroviral drugs and primary prophylaxis against these infections..$^{1-5}$ Although recent data have intensified the debate concerning the best time to begin antiretroviral therapy , ${ }^{6-8}$ primary prophylaxis against Pneumocystis carinii pneumonia, the commonest life threatening opportunistic infection, has been shown to reduce its incidence. ${ }^{9}$ Vaccination against pneumococcal infection is also recommended for infected subjects. ${ }^{10}$

To obtain maximum benefit from early treatment and primary prophylaxis people must be aware of their infection well in advance of the diagnosis of AIDS. We analysed awareness of HIV infection before diagnosis of AIDS in England and Wales. As antiretroviral and primary prophylaxis was not widely prescribed until 1988-9 our analysis was restricted to cases of AIDS diagnosed during January 1989 to December 1992.

\section{Subjects and methods}

Cases of AIDS in England and Wales are reported to our centre under a confidential voluntary scheme. ${ }^{11} \mathrm{We}$ analysed all reports of AIDS in adults received by the end of December 1992 in which AIDS was diagnosed during January 1989 to December 1992.

For this analysis we defined people having prolonged awareness of infection as those with more than nine months between their first positive HIV 
result and the date of diagnosis of AIDS, both of which are included on the AIDS reporting form. An interval of nine months was chosen as this allowed time for presentation to a doctor and, if appropriate, for the person to be stabilised on prophylactic drugs. Laboratory reports of newly recognised HIV-1 infections are also stored on a separate HIV database. Cross reference between this and the AIDS database by date of birth and an alphanumeric transformation of the surname (soundex code) of each infected person allowed the date of the first positive test result provided on the AIDS form to be validated. The date of birth or soundex code, or both, had not been provided by the reporting laboratory for some HIV reports, and it was therefore not possible to match them to AIDS cases. However, both a soundex code and date of birth were recorded on the AIDS form for all but two cases, which minimised the possibility of duplicate reporting of the same person. We excluded $571(14 \%)$ AIDS cases from the analysis as either a complete date of the HIV positive test result (561 cases) or the month of AIDS diagnosis (three), or both (seven) were not given. Results are presented for the 3556 adults for whom dates of first HIV positive test results and AIDS diagnosis were recorded.

The distribution of the incubation period for $\mathrm{HIV}$ is estimated to have a median of $8-10$ years, with $0 \cdot 4 \%$ of cases likely to have an incubation period of less than one year. ${ }^{12}$ Thus nearly all the people studied would have had an incubation period of over 10 months and would have had time to seek an HIV test before the onset of symptoms and been able to benefit from prophylaxis.

Logistic regression analyses were performed by using the statistical package GLIM, ${ }^{13}$ with the lack of prolonged awareness of HIV infection defined above as the outcome variable. Seven factors routinely recorded on the AIDS report form were examined for their association with this variable: exposure category, sex, age at diagnosis of AIDS, year of diagnosis, ethnic group, region of report, and region of residence. A further 367 cases were excluded from the logistic regression analyses as complete information on all variables was not available, as well as 29 cases probably infected through blood or tissue transfer.

To examine the effects of region of residence and region of report we divided the regional health authorities of England and Wales into two main geographical areas: Thames (the four Thames regional health authorities) and non-Thames. Region of report can be used as a proxy for region of care.

Cases were divided into four mutually exclusive exposure categories of probable virus acquisition: sex between men (including homosexual and bisexual men known to inject drugs), sex between men and women (not known to have injected drugs), injecting drug use by heterosexual men and women, and receipt of contaminated blood products.

\section{Results}

Of the 3556 adults who had AIDS diagnosed during January 1989 to December 1992 and for whom dates of diagnosis and of first HIV positive test result were unaware of their HIV infection up to nine months before AIDS was diagnosed

TABLE I-Interval between first positive HIV-1 antibody test result and diagnosis of AIDS

\begin{tabular}{|c|c|c|c|c|c|}
\hline \multirow{2}{*}{$\begin{array}{l}\text { Interval since } \\
\text { first test } \\
\text { (months) }\end{array}$} & \multicolumn{4}{|c|}{ Year of diagnosis } & \multirow[b]{2}{*}{ Total } \\
\hline & 1989 & 1990 & 1991 & 1992 & \\
\hline$\leqslant 9$ & 424 & 487 & 452 & 379 & 1742 \\
\hline$\leqslant 3$ & 379 & 434 & 393 & 332 & 1538 \\
\hline 4-9 & 45 & 53 & 59 & 47 & 204 \\
\hline$\geqslant 10$ & 357 & 437 & 510 & 510 & 1814 \\
\hline Total & 781 & 924 & 962 & 889 & 3556 \\
\hline
\end{tabular}

TABLE II-Odds ratios and $95 \%$ confidence intervals for variables independently associated with risk of being unaware of HIV infection up to nine months before diagnosis of AIDS

\begin{tabular}{|c|c|c|}
\hline Variable & Odds ratio & $\begin{array}{c}95 \% \\
\text { confidence } \\
\text { interval }\end{array}$ \\
\hline \multicolumn{3}{|l|}{ Region of report: } \\
\hline Thames & 1 & \\
\hline Non-Thames & 1.64 & 1.38 to 1.96 \\
\hline \multicolumn{3}{|l|}{ Exposure category: } \\
\hline Sex between men & 1 & \\
\hline Sex between men and women & $4 \cdot 46$ & 3.15 to 6.33 \\
\hline Injecting drug use & $1 \cdot 30$ & 0.85 to 1.99 \\
\hline Blood factor treatment & 0.01 & 0.001 to 0.08 \\
\hline \multicolumn{3}{|l|}{ Ethnic group: } \\
\hline White & 1 & \\
\hline Non-white & 1.99 & 1.51 to 2.61 \\
\hline \multicolumn{3}{|l|}{ Sex: } \\
\hline Male & 1 & \\
\hline Female & 0.50 & 0.33 to 0.76 \\
\hline \multicolumn{3}{|l|}{ Age (years)^: } \\
\hline $15-24$ & 1 & \\
\hline $25-34$ & $0 \cdot 72$ & 0.50 to 1.05 \\
\hline $35-49$ & 0.75 & 0.51 to 1.08 \\
\hline$\geqslant 50$ & 0.99 & 0.65 to 1.51 \\
\hline \multicolumn{3}{|l|}{ Year of diagnosis: } \\
\hline 1989 & 1 & \\
\hline 1990 & 0.81 & 0.65 to 1.00 \\
\hline 1991 & 0.62 & 0.50 to 0.77 \\
\hline 1992 & 0.48 & 0.39 to 0.60 \\
\hline
\end{tabular}

*The odds ratios for each category taken against the reference categor (15-24 years) give confidence limits overlapping 1 . However, testing for homogeneity over all four age categories shows significant variation with age (likelihood ratio $\chi^{2}=8 \cdot 10, \mathrm{df}=3 ;=0 \cdot 04$ )

known, 1742 (49\%) had been unaware of their seropositive status nine months or less before AIDS was diagnosed (table I). This included 204 people $(6 \%)$ who had had a first positive test result between four and nine months before AIDS was diagnosed. As their numbers are few treating them as "aware" would have made little impact on the analysis.

Of 806 people apparently unaware of their seropositive status and known to have died, $104(12.9 \%)$ died during the calendar month in which AIDS was diagnosed whereas only 51 of 834 of people $(6 \cdot 1 \%)$ who had been aware of their infection for at least 10 months died during the month of diagnosis of AIDS $(\mathrm{p}<0.01)$.

Factors significantly associated with lack of prolonged awareness of HIV infection after controlling for all other factors at the $5 \%$ significance level were year of diagnosis $(p<0.001)$, geographical area of report $(p<0.001)$, ethnic group $(p<0.001)$, exposure category $(p<0.001)$, sex $(p=0.0011)$, and age at diagnosis $(p=0.04)$ (table II). Geographical area of residence was not significant $(p=0 \cdot 12)$. There was no evidence of statistical interactions within the fitted models.

The percentage of people unaware of HIV infection before diagnosis of AIDS varied among the four main exposure categories and over time (figure). People who had received contaminated blood products were the most likely to have been aware of seropositive status while people who had probably contracted the virus through heterosexual intercourse seemed least likely to have been aware (tables II and III).

The probability of not having prolonged awareness of HIV seropositivity has significantly changed over time so that those diagnosed in earlier years were less likely to have a prolonged awareness of HIV infection than those diagnosed in 1992. People who had AIDS reported from the non-Thames regions were more likely to be unaware of their infection than those in Thames regions (odds ratio 1.64), and non-whites were more likely to be unaware than whites (1.99).

Women were less likely to be unaware of infection than men. Whereas $83 \%$ of men who had probably acquired the virus through sex with women (226 of 273 ) and $51 \%$ (41 of 80 ) of male drug injectors had apparently been unaware of their HIV infection, only $71 \%$ (143 of 201) of women who had probably acquired the virus through sex with men and $34 \%$ (12 of 35$)$ of 
TABLE III-Numbers (percentages) of people unaware of HIV infection up to nine months before diagnosis of AIDS according to variables examined

\begin{tabular}{|c|c|c|}
\hline Variable & $\begin{array}{c}\text { Number of } \\
\text { people }\end{array}$ & $\begin{array}{c}\text { No }(\%) \\
\text { unaware of }\end{array}$ \\
\hline \multicolumn{3}{|l|}{ Region of report: } \\
\hline Thames & 2674 & $1267(47)$ \\
\hline Non-Thames & 882 & $475(54)$ \\
\hline \multicolumn{3}{|l|}{ Region of residence: } \\
\hline Thames & 2544 & $1210(48)$ \\
\hline Non-Thames & 950 & $501(53)$ \\
\hline Not recorded & 62 & $31(50)$ \\
\hline \multicolumn{3}{|l|}{ Exposure category: } \\
\hline Sex between men & 2746 & $1252(46)$ \\
\hline Sex between men and women & 474 & $369(78)$ \\
\hline Injecting drug use & 115 & $53(46)$ \\
\hline Blood factor treatment & 140 & $2(1)$ \\
\hline Other or undetermined & 81 & $66(81)$ \\
\hline \multicolumn{3}{|l|}{ Ethnic group: } \\
\hline White & 2838 & $1306(46)$ \\
\hline Non-white & 481 & $353(73)$ \\
\hline Not recorded & 237 & $83(35)$ \\
\hline \multicolumn{3}{|l|}{ Sext: } \\
\hline Male & 3293 & $1568(48)$ \\
\hline Female & 263 & $174(66)$ \\
\hline \multicolumn{3}{|l|}{ Age (years): } \\
\hline $15-24$ & 193 & $100(52)$ \\
\hline $25-34$ & 1409 & $685(49)$ \\
\hline $35-49$ & 1563 & $745(48)$ \\
\hline$\geqslant 50$ & 391 & $212(54)$ \\
\hline \multicolumn{3}{|l|}{ Year of diagnosis: } \\
\hline 1989 & 781 & $424(54)$ \\
\hline 1990 & 924 & $487(53)$ \\
\hline 1991 & 962 & $452(47)$ \\
\hline 1992 & 889 & $379(43)$ \\
\hline
\end{tabular}

^Includes 50 men also known to have injected drugs.

tSee table II and text for testing as an independent variable.

female drug injectors had been unaware of their infection.

Although the risk of being unaware of infection was significantly different among the four age categories $(p=0.04)$, there was no obvious trend with age. Risk seemed higher in the 15-24 year and $\geqslant 50$ age groups and lower in the 25-34 and 35-49 year age groups (table II).

\section{Discussion}

Our analysis shows that six factors are strongly associated with lack of prolonged awareness of HIV infection: exposure category (sex between men and women), ethnic group (non-whites), area of first report of AIDS (outside the Thames regions), sex (male), year of diagnosis (earliest diagnosed cases), and age at diagnosis ( $15-24$ years and $\geqslant 50$ years).

People who are unaware of their serostatus before AIDS is diagnosed are unable to receive primary prophylaxis and antiretroviral treatment and have less time to accept their seropositive status and to build up a relationship with counsellors and support groups before becoming ill. ${ }^{14}$ They may be unaware of the importance of modifying their behaviour to avoid transmission of the virus to others and of the risks of mother to infant transmission in utero, at delivery, and through breast milk. ${ }^{1516}$ They are also more likely to die during the month in which AIDS is diagnosed than people who are aware of their infection.

REASONS FOR UNAWARENESS

Although region of report was strongly associated with lack of awareness of HIV infection, region of residence was not. This suggests that those more likely to be aware of their infection seek health care elsewhere. The comparative lack of awareness in non-whites may partly be due to patients from abroad. These patients may already be aware of their infection but their doctor in Britain requests an antibody test to confirm infection.

After controlling for exposure category and other factors, women were less likely to have been unaware of their infection than men. This may be because women have more frequent contact with health care services. The apparent lack of awareness among people aged $15-24$ years and $\geqslant 50$ years might reflect a lower perception of risk among these youngest and oldest of the sexually active population.

FACTORS AFFECTING ANALYSIS

Improved prophylactic treatment of HIV infection before AIDS is diagnosed may have delayed onset of AIDS in some people. This could have shifted some people who would have been in the unaware group into the aware group. As treatment details are not currently collected on the AIDS report form, the size of this effect is difficult to estimate but it may have contributed to the decrease over time in the proportion of people unaware of infection up to nine months before the diagnosis of AIDS.

Since the 571 cases excluded from the analyses constituted a sizeable proportion of the total number of cases diagnosed between January 1989 and December 1992 a more detailed examination of these was carried out for comparison with the 3556 cases analysed. No appreciable difference was found for any of the factors used in the logistic regression analysis.

People who are unaware that they have HIV infection are not necessarily unaware of their risk of being infected. They may have decided not to be tested because of denial, ignorance of available treatments, fear of stigmatisation, or fear of repercussions regarding employment, mortgages, life insurance, etc. There may also be a small group of people uninfected with HIV who fear that they are HIV positive and do not present for treatment of illnesses such as subacute bacterial endocarditis or tuberculosis.

\section{TREATMENT}

With increasing medical knowledge HIV infection is becoming a more manageable chronic disease. If the doctor is unaware that a patient is infected HIV related illnesses may not be recognised, which could delay appropriate treatment. Research has shown that the outcome for those with $P$ carinii pneumonia is better when it is diagnosed early. ${ }^{17}$ Nutritional deficiencies and weight loss can be early signs of HIV infection and dietary adjustments and supplements may be used to counteract these deficiencies. ${ }^{18}$ Further disadvantages exist for those not aware of their seropositive status. Women infected with HIV who have CD4 counts below $500 \times 10^{9} / 1$ and evidence of human papilloma virus infection may be at higher risk of developing neoplastic changes in the cervix and regular cervical screening is recommended in these women. ${ }^{1920}$

\section{Clinical implications}

- People infected with HIV can receive the benefits of treatment only if they know they are infected

- Almost half of those who had AIDS diagnosed were unaware of their HIV infection until within nine months before AIDS was diagnosed

- People aware of their HIV infection for a short period before diagnosis of AIDS were more likely to die in the month that AIDS was diagnosed

- The groups most likely to be unaware of their HIV infection were those infected through heterosexual exposure, those aged 15-24 and 50 and over, men, non-whites, and those with AIDS reported outside the Thames regions

- Health education needs to be reassessed to ensure it is reaching these groups 
Much has been achieved in the education of the general public about AIDS and the modes of transmission of HIV. Our results show, however, that over $70 \%$ of certain groups are unaware of their infection until within nine months before AIDS is diagnosed. The reasons for the failure to reach those individuals who most need to know require investigation. Recent initiatives by the Department of Health to encourage the provision of additional and more accessible HIV testing sites may encourage testing and reduce the likelihood of infection not being recognised until AIDS is diagnosed. Identifying those at risk of HIV infection, encouraging them to be tested, and encouraging those with positive results to seek medical care are necessary steps in providing an adequate health care programme for people infected with HIV.

We thank all clinicians and microbiologists who have contributed to the voluntary confidential reporting schemes for AIDS cases and newly diagnosed HIV infection.

\footnotetext{
1 Graham NMH, Zeger SL, Park LP, Phair JP, Detels R, Vermund SH, et al. Effects of zidovudine and Pneumocystis carinii prophylaxis on progression of HIV-1 infection to AIDS. Lancet 1991;338:265-9.

2 Graham NMH, Zeger SL, Kuo V, Jacobson LP, Vermund SH, Phair JP, et al. Zidovudine use in AIDS-free HIV-1 seropositive homosexual men in the Multicenter AIDS Cohort Study (MACS), 1987-1989. I Acquir Immune Defic Syndr 1991;4:267-76.

3 Hirschel B, Lazzarin A, Chopard P, Opravil M, Furrer H-J, Ruttimann S, et al. A controlled study of inhaled pentamidine for primary prevention of Pneumocystis carinii pneumonia. N Engl f Med 1991;324:1079-83.

4 Ragni MV, Kingsley LA, Zhou SJ. The effect of antiviral therapy on the natural history of human immunodeficiency virus infection in a cohort of natural history of human immunodeficiency virus infection

5 Volberding PA, Lagakos SW, Koch MA Perinelli C, Myers MW, Booth DK, et al. Zidovudine in asymptomatic human immunodeficiency virus infection a controlled trial in persons with fewer than $500 \mathrm{CD} 4$-positive cells per cubic millimetre. N Engl f Med 1990;322:941-9.

6 Hamilton JD, Hartigan PM, Simberkoff MS, Day PL, Diamond GR,
}

Dickinson GM, et al. A controlled trial of early versus late treatment with zidovudine in symptomatic human immunodeficiency virus infection. N Engl F Med 1992;326:437-43.

7 Fischl MA, Richman DD, Hansen N, Collier AC, Carey JT, Para MF, et al. The safety and efficacy of zidovudine (AZT) in the treatment of subjects with mildy symptematic human immuz) in the treate infection: a double-blind placebo-controlled trial. Ann Interm Med 1990;112:

Aboulker JP, Swart AM. Preliminary analysis of the Concorde trial. Lancet 1993;341:889-90

9 Recommendations for prophylaxis against Pneumocystis carinii pneumonia for adults and adolescents infected with human immunodeficiency virus. MMWR 1992;41:RR-4.

10 Department of Health. Immunisation against infectious disease. London: HMSO, 1992.

11 Public Health Laboratory AIDS Centre. The surveillance of HIV-1 infection and AIDS in England and Wales. Communicable Disease Repon 1991;5: R51-6.

12 Kuo J-M, Taylor JMG, Detels R. Estimating the AIDS incubation period from a prevalent cohort. Am Y Epidemiol 1991;133:1050-7.

13 Payne C, ed. The GLIM system manual for release 3.77. Oxford: Numerical Algorithms Group, 1983.

14 Drotman DP. Earlier diagnosis of human immunodeficiency virus (HIV) infection and more counselling. Ann Intern Med 1989;110:680-1.

15 European Collaborative Study. Children born to women with HIV infection natural history and risk of transmission. Lancet 1991;337:253-60.

16 De Martino M, Tovo P-A, Tozzi AE, Pezzotti P, Galli L, Livadiotti S, et al. HIV-1 transmission through breast milk: appraisal of risk according to duration of feeding. AIDS 1992;6:991-7.

17 Beck EJ, French PD, Helbert MH, Robinson DS, Moss FM, Harris JRW, $e$ al. Improved outcome of Pneumocystis carinii pneumonia in AIDS patients: a multifactorial treatment effect. International fournal of Sexually Transmitted Disease and AIDS 1992;3:182-7.

18 Baum MK, Mantero-Atienza E, Shor-Posner G, Fletcher MA, Morgan R, Eisdorfer $\mathrm{C}$, et al. Association of B6 status with parameters of immune function in early HIV-1 infection. I Acquir Immune Defic Syndr 1991;4:1122.

19 Klein RS, Adachi A, Fleming I, Ho GYF, Burk R. A prospective study of genital neoplasia and human papillomavirus in HIV infected women. In Proceedings of the VIII International Conference on AIDS, Amsterdam, Proceedings of the VIII International Conference on AIDS,

20 Regevik N, Sen P, Raska K, Raskova J, Middleton J, Nilsson S, et al. Cervical human papillomavirus in women infected with human immunodeficiency virus and its correlation with immune status and papanicolaou smear abnormalities. In: Proceedings of the VIII Intermational Conference on AIDS, Amsterdam, 1992. Netherlands: Congrex Holland, 1992. Abstract TuB0528.

(Accepted 5 May 1993)

The children's peak expiratory flow rates were within the normal range provided by the manufacturers of the mini-Wright peak flow meter ${ }^{1}$ in both parts of the study, and no deterioration was seen over the study period (figure). Children known to have asthma had

\section{Jacqueline E Crum}

Virkie, Shetland ZE3 9JS Jacqueline E Crum, paediatric registrar

$B M \mathcal{F} 1993 ; 307: 23-4$
Shortly after the grounding of the Braer oil tanker the previously unpolluted air of south Shetland began to smell strongly of oil, and some people experienced headaches and irritation of their eyes, throat, and skin. Adults suffering discomfort were given respirators but children were merely advised to avoid going outside. I conducted this study to ascertain whether the respiratory tracts of children were being affected.

\section{Subjects, methods, and results}

Children aged 5-12 years who were normally resident within $5 \mathrm{~km}$ of the Braer shipwreck all attended the same school. Three days after the shipwreck, I measured their peak expiratory flow at school using a mini-Wright peak flow meter (Airmed, Clement Clarke International, London). Three readings were taken, the maximum reading being recorded. I measured the children's height using a Raven minimeter (paediatric model, Raven Equipment, Essex) and asked them if they had asthma or had had respiratory symptoms before the shipwreck. Their replies were checked with their general practitioner. Peak expiratory flow measurements were repeated nine to 12 days after the shipwreck, by which time the strong smell of oil had abated. Tests of lung function (forced expiratory volume, peak expiratory flow, and forced vital capacity) were undertaken in the second half of the study with a pocket spirometer (Micro Medical, Kent), after measuring peak flow with the mini-Wright peak flow meter.

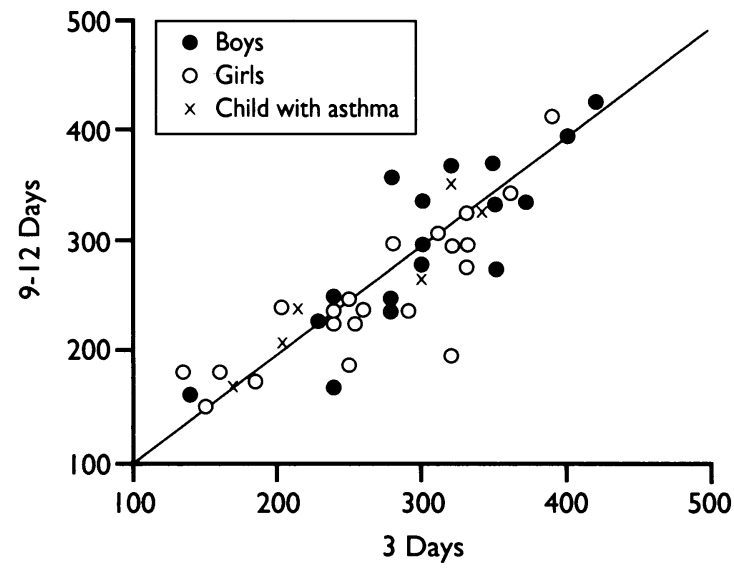

Comparison of peak expiratory flow rate ( $/ \mathrm{min}$ ) at three and nine to 12 days after shipwreck of $M V$ Braer

peak expiratory flow rates within the normal range (indicating excellent control of their asthma) and also showed no deterioration. Lung function tests gave normal results. Statistical analysis of the paired peak expiratory flow values (by Student's $t$ test for difference of means for paired samples) showed no significant difference between the two sets of values $(r=0.870$; $t=0.684 ; \mathrm{df}=19 ; \mathrm{p}=0.502)$.

Forty four children ( $79 \%$ of defined population) were studied at three days and $56(92 \%)$ at 9-12 days, which included all of the children originally studied. Some children were initially removed from the area because of parental concern, but most had returned by the time of the second part of the study. Parents were 